\title{
Nilai Dakwah dalam Tradisi A'dodoro' (Membuat Dodol) di Desa Lantang, Kecamatan Polongbangkeng Selatan, Kabupaten Takalar
}

\author{
${ }^{1}$ Herman, ${ }^{2}$ Rina, ${ }^{3}$ Nur Aisyah \\ ${ }^{1}$ STAI DDI MAKASSAR \\ ${ }^{2}$ Universitas Islam Negeri Alauddin Makassar \\ 1Hermanjama11295@gmail.com, 22Rina14429@gmail.com, \\ 32Nur.aisyah03032002@gmail.com
}

\begin{tabular}{l} 
Article Info \\
\hline Article history: \\
Received 29 November 2021 \\
Accepted 7 Januari 2022 \\
Published 8 Januari 2022 \\
Page : 47 - 55
\end{tabular}

Keyword:

Nilai Dakwah, Tradisi, a'dododro'

\begin{abstract}
The formulation of the problem studied in this study is How are Da'wah Activities in the A'dodoro Tradition in Lantang Village, South Polongbangkeng District, Takalar Regency? and What is the Value of Da'wah in the A'dodoro Tradition in Lantang Village, South Polongbangkeng District, Takalar Regency? The purpose of this study was to describe the activity of making dodol in Lantang Village, South Bontonmpo District, Takalar Regency and to find the value of da'wah in the tradition of making dodol in Lantang Village, South Polongbangkeng District, Takalar Regency. This study uses a descriptive qualitative research method where this type of research only tries to describe and analyze the A'dodoro Tradition as a Da'wah Activity in the Lantang area. The data were dug in depth with interview, observation and documentation techniques. The results of this study indicate that the value of da'wah contained in the a'dodoro tradition is the value of community solidarity, the value of generosity and the value of gratitude.
\end{abstract}

Rumusan masalah yang dikaji dalam penelitian ini adalah Bagaimana Aktivitas Dakwah dalam Tradisi A'dodoro' di Desa Lantang, Kecamatan Polongbangkeng Selatan, Kabupaten Takalar? dan Bagaimana Nilai Dakwah dalam Tradisi A'dodoro' di Desa Lantang, Kecamatan Polongbangkeng Selatan, Kabupaten Takalar? Tujuan penelitian ini adalah untuk menggambarkan aktivitas membuat dodol di Desa Lantang, Kecamaan Bontonmpo Selatan, Kabupaten Takalar serta untuk menemukan nilai dakwah dalam tradisi membuat dodol di Desa Lantang, Kecamatan Polongbangkeng Selatan, Kabupaten Takalar. Penelitian ini menggunakan metode penelitian kualitatif yang bersifat deskriptif dimana jenis penelitian ini hanya berusaha menggambarkan serta menganalisis Tradisi A'dodoro' Sebagai Aktivitas Dakwah Di Daerah Lantang. Data-data digali secara mendalam dengan teknik wawancara, observasi dan dokumentasi. Hasil penelitian ini menunjukkan, bahwa nilai dakwah yang terkandung dalam tradisi a'dodoro yaitu nilai solidaritas keummatan, nilai kedermawanan dan nilai kesyukuran.

Copyright (C) 2022 Journal Of Islamic Management. All rights reserved.

Editorial Office:

Program Studi Manajemen Dakwah, Fakultas Dakwah dan Komunikasi, UIN Sunan Ampel Surabaya.

Jl. Ahmad Yani 117 Surabaya, Jawa Timur, Indonesia.

Email:jim@uinsby.ac.id 


\section{Pendahuluan}

Islam adalah agama monoteisme terakhir yang diturunkan oleh Allah Swt. Sebagai suatu rahmat bagi seluruh alam raya. Ajaran Islam didalamnya mengandung ajaran hanif, lurus, dan diyakini sebagai penyempurna bagi agama-agama sebelumnya. ${ }^{1}$ Ajaran Islam secara esensi tidak bisa lepas dari kenyataankenyataan adanya hubungan antarmanusia dan zat ketuhanan yang dianggap sakral. ${ }^{2}$ Islam adalah agama dakwah, agama yang menyebarluaskan kebenaran dan mengajak orang-orang yang belum mempercayai untuk percaya, menumbuhkan pengertian dan kesadaran agar umat Islam mampu menjalani hidup sesuai dengan perintah Allah swt. Nilai-nilai kebenaran dan kebaikan dalam Islam wajib disebarluaskan (dakwah) oleh manusia kepada manusia lain sebab dakwah merupakan tugas suci dan wajib bagi seluruh umat muslim.

Dakwah sebagai metode penyebaran agama Islam merupakan segala bentuk aktivitas penyampaian ajaran Islam kepada orang lain dengan berbagai cara bijaksana agar memahami dan mengamalkan ajaran Islam dalam semua lapangan kehidupan. "Berbagai cara bijaksana" itu mestilah dilaksanakan dengan seperangkat ilmu yang dikenal sebagai ilmu dakwah. ${ }^{3}$ Dakwah adalah suatu kegiatan yang bisa dilakukan secara induvidu maupun kelompok. Hal ini dikarenakan jankauan dari dakwah itu sendiri

${ }^{1}$ Aizid, Rizem. Sejarah Peradaban Islam Terlengkap. Diva Press, 2015.

${ }^{2}$ Syamsuddin, Pengantar Sosiologi Dakwah (Jakarta; Kencana, 2016), h. 60.

${ }^{3}$ Siregar dan Mawardi, Menyeru Tanpa Hinaan (Upaya Menyemai Dakwah sangatlah luas. Salah satunya adalah bagaimana tradisi dari masyarakat menjadi bagian dari aktivitas dakwah itu sendiri.

Berbagai macam metode penyampaian kebaikan yang menggunakan kebiasaan masyarakat lokal sampai dengan melibatkan Agama yaitu Dakwah. Dakwah adalah mewujudkan kebahagiaan dan kesejahteraan hidup di dunia dan akhirat yang diridhai oleh Allah SWT. Yakni dengan menyampaikan nilai-nilai yang dapat mendatangkan kebahagiaan dan kesejahteraan yang diridhai Allah SWT sesuai dengan segi atau bidangnya masing-masing.

Dalam kehidupan di tengah masyarakat, seringkali dakwah diartikan sebagai tugas ulama sebagai pendakwah menyampaikan pesannya di hadapan khalayak. Akhirnya dakwah dipahami sebagai tugas ulama semata. Bentuk dakwah hanya ceramah agama dan mitra dakwah selalu terdiri banyak orang. Pemahaman yang tidak tepat ini telah di terima secara umum oleh masyarakat sehingga perlu dikemukakan beberapa fenomena dakwah yang lain. Dakwah bukan hanya kewenagan ulama atau tokoh agama. Setiap muslim bisa melakukan dakwah, karena dakwah bukan hanya ceramah agama saja. ${ }^{4}$

Tradisi secara umum dikenal sebagai suatu bentuk kebiasaan yang memiliki rangkaian peristiwa sejarah kuno. Setiap tradisi dikembangkan untuk beberapa maksud dan tujuan , seperti tujuan pembelajaran secara spiritual, tujuan politis atau tujuan

Humanis Pada Masyarakat Kota Langsa yang Pluralis). Jurnal Dakwah 16.2 (2015): h. 203-229.

${ }^{4}$ Aziz, Moh Ali. Ilmu Dakwah: Edisi Revisi. Prenada Media, 2019. hal 1 
budaya dalam beberapa masa. Jika kebiasaan sudah diterima oleh masyarakat dan dilakukan secara berulang, maka segala tindakan yang bertentangan dengan kebiasaan akan dirasakan sebagai perbuatan yang melanggar hukum. Karena manusia adalah makhluk berbudaya, mereka tumbuh dan berkembang dengan kebudayaan atau tradisi dimana mereka berada. Kebudayaan atau tradisi memberikan andil yang cukup besar karena berisi simbol-simbol yang memiliki. Nilai-nilai kebudayaan lokal Makassar yang punya relevansi dengan ajaran Islam dan sesuai dengan rutinitas yang melekat pada masyarakat Makassar. Adanya berbagai nilai-nilai kebudayaan lokal yang relevan dengan nilai-nilai Islam ini, harus disampaikan saja. ${ }^{5}$ Tradisi tersebut mempunyai makna atau arti tersendiri dimata masyarakat yang melestarikannya. Ada banyak tradisi dengan tujuan yang yang berbeda beda dan nilai yang terdapat dibalik tradisi tersebut. Salah satu tradisi yang popular ada di Indonesia adalah Tradisi A'dodoro' sebelum Panen. Tradisi ini berkembang di Daerah asal Kab. Takalar yang terus menerus dijaga dan dilestarikan tiap tahun. Salah satu yang menarik dari tradisi ini adalah nilai Gotong Royong masyarakat setempat. Dari tradisi inilah nilai dakwah dapat kita lihat secara tidak lansung.

\section{Kajian Pustaka \\ 1. Budaya lokal}

5Herman, H. Dakwah Bahasa

Lokal Pada Masyarakat Kecamatan

Bontonompo Selatan Kabupaten

Gowa. Jurnal Dakwah Tabligh, 21(1), 105121.

${ }^{6}$ Irawan, D., \& Suriadi, S. (2020).

Komunikasi Dakwah Kultural di Era
Menurut Baharudin Ali bahwa kultural atau kebudayaan berasal dari suatu adat masyarakat. Maka kebudayaan adalah hasil ciptaan manusia yang terus dijalankan secara berkelanjutan. Budaya berarti adat istiadat atau sesuatu yang sudah menjadi kebiasaan yang sudah sukar diubah. ${ }^{6}$ Para ahli kebudayaan memberi pengertian budaya lokal sebagai berikut:

a. Superculture, kebudayaan yang berlaku bagi seluruh masyarakat, contohnya kebudayaan nasional.

b. Culture, lebih khusus, misalnya berdasarkan golongan etnis, profesi, wilayah atau daerah, contohnya budaya Sunda.

c. Subculture, merupakan kebudayaan khusus dalam sebuah culture, tetapi tidak bertentangan dengan kebudayaan induknya, contohnya budaya gotong royong.

d. Counter-culture, tingkatannya sama dengan subculture, yaitu bagian turunan dari culture, tetapi counter-culture ini bertentangan dengan kebudayaan induknya, contoh budaya individualisme. ${ }^{7}$

Berdasarkan skema sosial budaya yang ada di Indonesia, yang terdiri atas masyarakat yang bersifat majemuk dalam struktur sosial, budaya dan ekonomi, budaya lokal berada pada tingkat culture. Hal ini jika dilihat dari struktur dan tingkatannya.

Dalam kebudayaan tedapat dimensi-dimensi budaya lokal yaitu: 1. Dimensi pengetahuan Lokal

Millennial. Alhadharah: Jurnal Ilmu Dakwah, 18(2).

${ }^{7}$ Kholidah, N. R. J. (2020, January). Eksistensi Budaya Lokal Sebagai Penguat Nasionalisme. In Prosiding SNP2M (Seminar Nasional Penelitian dan Pengabdian Masyarakat) UNIM (No. 2, pp. 168-174). 
Dimensi pengetahuan lokal terkait dengan perubahan dan siklus iklim, kemarau dan penghujan, jenis flora dan fauna, dan kondisi geografi, demografi, serta sosiografi. Bagi masyarakat lokal yang telah tinggal cukup lama dalam sebuah wilayah dan telah paham dengan perubahanm sosial yang bervariasi telah menghadirkan kemampuan adaptasi terhadap lingkungannya. Kemampuan adaptasi ini memberikan pengetahuan lokal dalam menghadapi dan menguasai perubahan alam.

2. Dimensi nilai lokal

Dalam mengatur kehidupan antar masyarakat maka harus memiliki nilai-nilai lokal yang mengatur hubungan manusia dengan tuhanya, hubungan manusia dengan manusia, dan hubungan manusia dengan alam. Nilai-nilai memiliki dimenisi waktu yaitu berupa nilai masa lalu, masa kni dan masa yang akan datang. Nilai-nilai tersebut akan mengalami perubahan sesuai dengan denagn kemajuan masyarakat.

3. Dimensi keterampilan lokal

$$
\text { Keterapilan lokal bagi }
$$
masyarkat digunakan sebagai kemampuan bertahan hidup. Keterapilan lokal dari yang sederhana seperti berburu, meramu, bercocok tanam sampai mebuat industri rumah tangga. Keterapilan lokal hanya mampu memenuhi kebutuhankebutuhan keluarganya masingmasing atau disebut ekonomi substensi.

\section{Dimensi sumber daya lokal}

Pada umumnya sumber daya alam tidak dapat diperbarui dan yang dapat diperbarui. Masyarakat akan mempergunakan sumber daya lokal sesaui dengan kebutuhannya dan tidak akan mengekploitasi secara

\footnotetext{
${ }^{8}$ Muh. Ilham, Budaya Lokal dalam Ungkapan Makassar Dan Relevansinya
}

besar-besaran atau dikomersialkan. Sumber daya lokal sudah dibagi peruntukannya seperti hutan, kebun, sumber air, lahan pertanian, dan pemukiman. Kepemilikan sumber daya lokal ini biasanya bersifat kolektif.

5. Dimensi mekanisme pengambilan keputusan

Setiap masyarakat pada dasarnya memiliki pemerintah lokal sendiri atau disebut pemerintah kesukuan. Suku merupakan kesatuan hukum yang memerintah warganya agar bertindak sebagai warga masyarakat. Masing-masing masyarakat memiliki mekanisme pengambilan keputusan yang berbeda-beda, ada yang melakukan secara demokratis atau duduk sama rendah berdiri sama tinggi. Ada juga masyarakat yang melakukan secara hirarki, bertingkat, atau berjenjang.

6. Dimensi solidaritas kelompok Masyarakat umumnya dipersatukan oleh ikatan komunal untuk membentuk solidaritas lokal. Setiap masyarakat memiliki mediamedia yang mampu mengikat wargawarganya dilakukan melalui ritual keagamaan atau acara dan upacara adat lainnya. Masing-masing anggota masyarakat memberi dan menerima sesuai dengan bidang dan fungsinya, seperti solidaritas mengelola tanaman padi, kerja bakti dan gotong royong. ${ }^{8}$

\section{Dakwah}

Dakwah kultural merupakan suatu proses usaha dalam mengajak dengan menekankan pendekatan yang meninjau Kembali kaitan doktrinasi yang formal antara islam dan politik, atau islam dan negara (Islam Kultural) dengan tujuan agar manusia beriman kepada Allah SWT. Percaya

Dengan Sarak; Suatu Tinjauan Pemikiran Islam, h. 19-20. 
dan mentaati nilai-nilai keislaman yang dibawah oleh Nabi Muhammad saw. Supaya menyembah Allah Swt. Agar selamat di dunia dan di akhirat. ${ }^{9}$

Setelah memahami pengertian dakwah maka pola dakwah kultural diantaranya yaitu:

1) Dakwah kultural dalam konteks budaya lokal: Yaitu mencari bentuk pemahaman dan upaya yang lebih emnatik dan mengapresiasi kebudayaan masyarakat yang menjadi sasaran dakwah.

2) Dakwah kultural dalam konteks budaya global: Mengkaji secara mendalam titik silang antara islam dan budaya global. Baik secara teoritik dan embirik. Seperti memberkan subtansi atau pesan dakwah. Memperhatikan media atau wahana dakwah serta memperhatikan obyek dakwah.

3) Dakwah kultural melalui oprasi seni: Budaya termasuk seni khususnya adalah ekspresi dari perasaan sosial yang bersiafat kolektif sehingga merupakan ungkapan yang sesungguhnya dari kehidupan masyarakat. Dengan mengembangkan seni yang ma'ruf maka dakwah kultural bisa berperan untuk melahirkan inovasi dan kreasi.

4) Dakwah kultural melalui media: Yaitu dakwah dengan cara menggunakan teknologi sebagai media untuk mencapai tujuan dakwah.

5) Dakwah kultural gerakan jamaah atau dakwah jamaah :Yaitu fokus pada pemberdayaan dan pengembangan masyarakat melalui pembentukan jamaah sebagai satuan sosial (komunitas)

${ }^{9}$ Muhammad Sulton, Desain Ilmu Dakwah Kajian Antalogi, Epistimologi, dan
Dalam struktural adalah gerakan dakwah yang berda pada kekuasaan para aktivis dakwah struktural bergerak mendakwahkan ajaran islam dengan memanfaatkan struktural sosial, politik, maupun ekonomi yang ada guna menjadikan islam sebagai ideologi negara. Nilainilai islam menjelama kedalam kehidupan berbangsa dan bernegara. Dakwah struktural memegang tesis bahwah dakwah yang sesungguhnya adalah akitivisme islam yang berusaha mengwujudkan negara bangsa yang berdasarkan islam, para pelaku politik menjunjung tinggi nilai keislaman dalam perilaku politik serta mengakkan ajaran islam menjadi tanggung jawab negara dan kekuasaan. Dalam persepektif dakwah kultural negara adalah instrumen penting dalam kegiatan dakwah.

\section{Metode Penelitian}

Penelitian ini menggunakan metode penelitian kualitatif yang bersifat deskriptif dimana jenis penelitian ini hanya berusaha menggambarkan serta menganalisis Tradisi A'dodoro' Sebagai Aktivitas Dakwah Di Daerah Lantang.

\section{Hasil dan Pembahasan}

Kehadiran budaya lokal mempengaruhi setiap interaksi antar masyarakat dan intra masyarakat. Termasuk bahasa sebagai bagian dari budaya lokal berpengaruh terhadapat komunikasi masyarakat, mulai dari hanya berkomunikasi biasa sampai penerimaan makna pesan komunikasi. Bagi masyarakat lokal bahasa lokal merupakan media komunikasi yang mempermudah penangkapan pesan kebaikan.

Aksiologi (Semarang: Pustaka Belajar, 2003), h.26 
Masyarakat umumnya dipersatukan oleh ikatan kesukuan untuk membentuk solidaritas lokal. Setiap wilayah memiliki berbagai macam media yang mampu mengikat solidaritas warganya dilakukan melalui ritual keagamaan atau acara dan upacara adat lainnya. Masingmasing anggota masyarakat memberi dan menerima sesuai dengan bidang dan fungsinya, seperti solidaritas mengelola tanaman padi, kerja bakti dan gotong royong. ${ }^{10}$

\section{Nilai Solidaritas Keummatan}

Manusia dalam kehidupannya akan mengalami banyak interaksi dengan manusia yang lain. Interaksi itulah yang menumbuhkan keakraban yang berujung pada tumbuhnya solidaritas kelompok lokal. Masyarakat hidup dan ditumbuhkan oleh agama dan budaya. Setiap daerah memiliki kebudayaan yang akan kokoh di pertahankan oleh penganutnya, karena menganggap kebudayaan memberikan satu semangat kehidupan bermasyarakat yang beradap dan beretika. Sulawesi Selatan sebagai salah satu wilayah di indonesia yang memilki tradisi kebudayaan yang mempesona. Tradisi-tradisi kebudayaan masingmasing di miliki oleh suku-suku yang berdiam di wilayah Sulawesi Selatan. Suku Makassar yang berdiam di daerah Pangkep, Maros, Makassar, Gowa, Takalar, Jenepono dan Bantaeng, masing-masig memilki tradisi tersendiri, walaupun samasama suku. Di Kabupaten Takalar, Kecamatan Polongbangkeng Selatan Desa Lantang, Kabupaten Takalar, memiliki suatu tradisi perayaan setiap tahunnya setelah panen padi dilaksanaakn oleh masyarakatnya.

\footnotetext{
${ }^{10}$ Muh. Ilham, Budaya Lokal dalam Ungkapan Makassar Dan Relevansinya
}

Tradisi itu disebut tradisi A'dodoro' atau tradisi membuat dodol. Tradisi dalam A'dodoro' memberikan pengaruh persaudaraan dalam proses pembuatanya. Hal ini didasari oleh orang-orang yang terlibat dalam pembuatan dodol. Terlihat dari banyaknya orang yang ikut berpartisipasi dalam kegiatan A'dodoro'. Orang-orang yang berpartisipasi didalamnya menunjukkan kepekaan terhadap orang lain dan ikut serta dalam pembuatannya. Setiap orang akan mendapatkan giliran untuk mengambil bagian dalam aktivitas A'dodoro.. Bagian bagian yang dimaksudkan dalam hal ini yaitu mengaduk dodol. Artinya setiap waktu dalam pembuatan dodol itu orang-orang tidak boleh berhenti mengaduk untuk menghindari kegagalan dalam pembuatannya. Dari interaksi sederhana itulah para tokoh masyarakat yang terlibat dalam pembuatan dodol membangun silahturahminya dan memperkokoh persaudaraanya. Dalam pola dakwah kultural sebagaimana yang disebutkan di tinjauan teoretis, bahwa Dakwah kultural sebagai konteks budaya lokal, berarti mencari bentuk pemahaman dan upaya yang mengapresiasi kebudayaan masyarakat yang didalamnya terdapat pesan-pesan dakwah. Dalam aktivitas kebudayaan, didalamnya ada upaya menyapaikan dan mengimpelmentasi kebaikan yang menjadi indikasi kuat bahwa dalam budaya ada nilai dan pesan dakwah. Dengan dasar itu maka sangat kuat kesimpulan bahwa dalam tradisi membuat dodol (A'dodoro') ada pesan dan makna dakwah pula didalamnya yakni pertama, nilai Solidaritas keummatan yang Islam, h. 19-20. 
ditunjukkan secara jelas dalam proses membutan dan perayaannya.

\section{Nilai Kedermawanan}

Gerakan dakwah tidak harus disempitkan hanya dengan berbicara di atas mimbar dengan menyembutkan dalil-dalil al-Qur'an dan Hadist, namun banyak macam dalam menyebarkan atau mengajak manusia kepada kebaikan. Kehidupan sosial tidak bisa dipungkiri bahwa, kebudayaan kuat mengikat persaudaran. Muhammad Ali Aziz dalam Bukunya Ilmu dakwah menyampaikan bahwa fungsi dakwah yaitu melestarikan nilai-nilai keislaman dari generasi ke generasi agar tidak terputus. ${ }^{11}$ Dalam konteks ini, melestarikan nilai-nilai keislaman harus menyusuaikan dengan keadaan masyarakat yang berbudaya. Bahkan menjadikan formulasi kebudayaan sebagai aktivitas dakwah Islam, artinya dalam kebudayaan ada konteks dakwah dan melestarikan nilai-nilai Islam dari generasi ke generasi. A'Dodoro' sebagai sebuah kebudayaan yang masih terjaga dan dilestarikan sampai hari ini bukan karena tanpa sebab. Masyarakat Desa Lantang, Kecamatan Polongbangkeng Selatan, Kabupaten Takalar dan sekitarnya menyadari bahwa dalam tradisi ini mengandung nilai dan pesan Islam. Dalam tahapan pembuatan sampai prosesi perayaan didalamnya memiliki relefansi dengan Islam. Ketika nilai dan pesan pertama adalah solidaritas keummatan, yang kedua adalah pesan dan nilai kedermawanan atau sedekah.

Buktinya adalah dodol yang telah selesai proses pembuatannya, yaitu telah diolah-dikemas dan telah

${ }^{11}$ Mohammad Ali Aziz, Ilmu

Dakwah, (Jakarta: Kencana, 2004), hlm. 59. melalui proses tradisi atau didoakan, maka masyarakat berbondongbondong untuk mensedekahkan dodol tersebut kepada masyarakat luas yang ada disekitar wilayah, pengunjung dan anak yatim. Kenikmatan sebagai manusia, salah satunya ketika bisa saling memberi dan membantu sesama masyarakat. Aktivitas ini, kembali menambah asumsi, bahwa tradisi didalamnya memiliki relevansi dengan ajaran Islam atau dalam artian, tradisi bisa menjadi media dakwah. Sebagai sebuah kebudayaan yang melibatkaan banya orang menjadikan tradisi $A$ 'dodoro' sebagai jalan dakwah yang efektif dalam penyampaian nilai dan pesannya. Dalam dimensi nilai lokal telah dijelaskan bahwa upaya menata kehidupan bermasyarakat maka harus memiliki nilai-nilai lokal yaitu didalamnya ada nilai upaya menata hubungan manusia dengan tuhanya (habluminallah), hubungan manusia dengan manusia (habluminannas), dan hubungan manusia dengan alam. Dengan dasar ini, Antara dimensi nilai lokal dengan dimensi nilai ajaran Islam sangat jelas memiliki orientasi dimensi nilai yang selaras. Gerakan aktualisasi nilainya memang bisa berbeda namun secara esensi sama saja. Sehingga muncullah dakwah kultural, dengan prinsipnya yang sederahan kultur atau kebudayaan masyarakat secara esensi memiliki nilai dakwah. Tradisi A'dodoro' dengan aktualisasi tradisinya saling berbagi atau mensedehkahkan dodol yang telah selesai prosesnya kepada sesama. Gerakan ini, kita sangat sepakat baik secara dimensi lokal atau bahkan dimensi nilai Islam. Hal ini merupakan bentuk kedermawanan atau bentuk kebaikan yang disenangi 
oleh Allah swt. Kedermawanan disini, menjadi sebuah nilai Islam yang diimplementasikan melalui gerakan tradisi-budaya. Mereka yang ada diwilayah tradisi a'dodoro' termasuk para tamu yang datang berkunjung akan mendapat dodol sebagai buah tangan, dan Sebagian lainnya diberikan kepada anak yatim yang berada disekitaran Desa Lantang Kecamatan Polongbangkeng Selatan, Kabupaten Takalar.

\section{Nilai Kesyukuran}

Nilai dakwah ke tiga yang terkandung dalam tradisi membuat dodol yaitu nilai kesyukuran. Tardisi tahunan ini, merupakan aktivitas budaya sebagai bentuk rasa syukur kepada Allah swt. atas nikmat yang diberikan. Setelah panen raya padi selesai, maka waktunya tradisi a'dodoro dilaksanakan sebagai bentuk kesyukuran atas panen yang didapatkan oleh masyarakat. Menurut Saad Riyadh, dalam bukunya Jiwa dalam Bimbingan Rasulullah, menjelaskan bahwa bentuk syukur manusia tersusun dari tiga aspek, yaitu ilmu pengetahuan, hal/keadaan, dan amal perbuatan, sebagai sifatsifat yang menjadi rangkaian menuju penyucian diri (tazkiyatun nafs). ${ }^{12}$

Rangkaian-rangkain tradisi a'dodoro' sebagai bentuk perbuatan atas nikmat Allah swt. yang telah melimpahkan hasil panen yang didapatkan. Dalam tradisi tersebut tentu memiliki latar belakang sejarah dan ilmu pengetahuan yang kaya, dengan keadaan yang hanya satu tahun sekali setalah panen raya, dengan perbuatan, dodol yang telah dibuat disedekahkan untuk rang lain, yaitu masyarakat sekitar, pengunjung dan anak yatim. Hal-hal tersebut senada dengan tulisan Saad Riyadh, dalam bukunya Jiwa dalam Bimbingan Rasulullah, yang artinya seluruh komponen syukur ada dalam tradisi a'dodoro' yang dilaksanakan di Desa Lantang, Kecamatan Polongbangkeng Selatan, Kabuapaten Takalar. Wujud syukur yang ditunjukkan oleh masyarakat melalui nilai tradisi memberikan penguatan kesimpulan bahwa tradisi kebudayaan a'dodoro' dilaksanakan dengan muatan dakwah kultural yang kuat dan syarat makna didalamnya. Hal ini sekaligus menumbuhkan pemahaman bahwa tradisi kebudayaan tidak selamanya bertentangan dengan ajaran Islam. Sebab, nenek moyang tentu memiliki ilmu dan adab dalam menjaga hubungannya dengan sang pencipta, dengan sesama dan dengan alam semesta.

\section{KESIMPULAN.}

Tradisi kebudayaan A'dodoro' (membuat dodol) di Desa Lantang Kecamatan Polongbangkeng Selatan, Kabupaten Takalar merupakan aktivitas yang memuat dakwah kultural dengan dimensi nilai-nilai lokal yang selaras dengan dimensi nilai-nilai Islam. Masyarakat masih aktif melaksanaan tradisi dan terus melestarikannya. Pesan dan nilai dakwah yang terkandung dialam tardisi a'dodoro' atau membuat dodol yaitu nilai solidaritas keummatan, nilai kedermawanan dan nilai nilia kepedulian sesama masyarakata terlihat dalam aktivitas A'dodoro (membuat dodol) sebagai salah satu perayaan tahunan masyarakat.

\footnotetext{
${ }^{12}$ Saad Riyadh, Jiwa dalam Bimbingan Rasulullah, (Jakarta: Gema Insani, 2007), hlm. 137
} 


\section{Daftar Pustaka}

Aizid, Rizem. Sejarah Peradaban Islam Terlengkap. Diva Press, 2015.

Ali, Mohammad Aziz, Ilmu Dakwah, Jakarta: Kencana, 2004.

Aziz, Moh Ali. Ilmu Dakwah: Edisi Revisi. Prenada Media, 2019.

Herman, H. Dakwah Bahasa Lokal Pada Masyarakat Kecamatan Bontonompo Selatan Kabupaten Gowa. Jurnal Dakwah Tabligh, 21(1).

Ilham, Muh., Budaya Lokal dalam Ungkapan Makassar Dan Relevansinya Dengan Sarak; Suatu Tinjauan Pemikiran Islam.

Irawan, D., \& Suriadi, S. (2020). Komunikasi Dakwah Kultural di Era Millennial. Alhadharah: Jurnal Ilmu Dakwah, 18(2).

Kholidah, N. R. J. (2020, January). Eksistensi Budaya Lokal Sebagai Penguat Nasionalisme. In Prosiding SNP2M (Seminar Nasional Penelitian dan Pengabdian Masyarakat) UNIM. No. 2, pp.

Saad Riyadh, Jiwa dalam Bimbingan Rasulullah, Jakarta: Gema Insani, 2007.

Siregar dan Mawardi, Menyeru Tanpa Hinaan (Upaya Menyemai Dakwah Humanis Pada Masyarakat Kota Langsa yang Pluralis). Jurnal Dakwah 16.2 (2015).

Sulton, Muhammad, Desain Ilmu Dakwah Kajian Antalogi, Epistimologi, dan Aksiologi. Semarang: Pustaka Belajar, 2003.
Syamsuddin, Pengantar Sosiologi Dakwah. Jakarta; Kencana, 2016. 